\title{
Glycans and Glycan-Binding Proteins in Atherosclerosis
}

\author{
Veit Eckardt ${ }^{1}$ Christian Weber ${ }^{1,2}$ Philipp von Hundelshausen ${ }^{1,2(0)}$ \\ ${ }^{1}$ Institute for Cardiovascular Prevention, Faculty of Medicine, \\ Ludwig-Maximilians-Universität München, Munich, Germany \\ ${ }^{2}$ German Centre for Cardiovascular Research, Partner Site Munich

\begin{abstract}
Address for correspondence Philipp von Hundelshausen, MD, Institute for Cardiovascular Prevention, Pettenkoferstrasse 9, D-80336 München, Germany (e-mail: phundels@med.Imu.de).
\end{abstract} Heart Alliance, Munich, Germany

Thromb Haemost 2019;119:1265-1273.
Abstract
Keywords
- glycocalyx
- glycosaminoglycan
- chemokine
- selectin
- galectin
- low-density lipoprotein

Complex glycans are readily accessible on the endothelium and on cell and plasma components. They interact with glycan-binding proteins which translate their structure into function. Advanced analytical tools are available to investigate their structure and functional interactions. Modifications to glycan structures which alter their capacity to bind proteins are particularly relevant in atherosclerosis. We summarize the regulatory role of glycans and their binding partners in the development of the disease. Given their complexity, accessibility, and important functional role, glycans and glycan-binding proteins represent promising diagnostic tools and therapeutic targets.

\section{Introduction}

Glycans are carbohydrate structures that contain more than one monosaccharide unit. The human glycome, the pool of all mainly extracellular glycans, is a complex, universal, and dynamic system which confers biological information. ${ }^{1,2}$ Glycans represent a profile of the condition and environment of cells which is read and translated into function by glycanbinding proteins (GBPs). Advanced biochemical tools are at hand to investigate the pathophysiological role of glycans which rely in part on their interaction with GBPs. Vascular glycans regulate the interaction between circulating cells, plasma components, and endothelial cells, and contain numerous GBPs. Therefore, alterations in the vascular glycome are associated with vascular disease and particularly the pathogenesis of atherosclerosis which is characterized by endothelial dysregulation, platelet adhesion, leukocyte recruitment, and accumulation and phagocytosis of lipoproteins. Moreover, specific glycan structures and GBPs are suitable therapeutic targets and agents. This article sum-

Note: The review process for this paper was fully handled by Gregory Y. H. Lip, Editor-in-Chief.

(D) Philipp von Hundelshausen's ORCID is https://orcid.org/0000-00017474-9370.

received

March 8, 2019

accepted after revision

May 14, 2019

marizes their pathophysiological relevance and diagnostic and therapeutic potential.

\section{The Discovery of Glycans and GBPs}

The role of glycans and GBPs in vascular biology has been known for over a century. Landsteiner described the first glycan determinants, the blood groups, at the turn of the century. ${ }^{3}$ Watkins and Morgan later revealed that glycan structures create the blood group phenotypes. They were among the first to describe the presence of glycans on the cell surface. ${ }^{4,5}$ The discovery of the ABO system revolutionized transfusion medicine. Recently, genome-wide association studies showed that subjects with specific singlenucleotide polymorphisms (SNPs) in the ABO gene locus are at higher risk for coronary artery disease and myocardial infarction. ${ }^{6,7}$ In some cases, these SNPs can be linked to a non-O phenotype. ${ }^{8}$ Although the reasons for this correlation remain unclear, blood group glycans are also expressed on platelets and glycoproteins (GPs), and the ABO locus is associated with platelet function and plasma levels of von Willebrand factor (VWF) and low-density lipoprotein (LDL). ${ }^{6-9}$

Stillmark isolated the first GBP, ricin, the hemagglutinating component of plant seed extracts. ${ }^{10}$ When the blood group specificity of hemagglutinins was discovered, they

(c) 2019 Georg Thieme Verlag KG Stuttgart · New York
DOI https://doi.org/ 10.1055/s-0039-1692720. ISSN 0340-6245. 
were termed "lectins" (from Latin legere = to read, collect, select). ${ }^{11,12}$ In the 1920 s, Howell discovered heparin, the most prominent glycosaminoglycan (GAG) in clinical use. The resolution of its structure and its first application in the prophylaxis of venous thrombosis followed in the 1930s. Its anticoagulant mechanism, that is, the inactivation of factor $\mathrm{Xa}$ and thrombin by interaction with antithrombin, was described 40 years later. ${ }^{13-15}$

The aforementioned discoveries suggest a strong link between the pathophysiological relevance of glycans and their capacity to bind GBPs.

\section{GBPs Translate Glycan Structures into Function}

The human glycome is built from 10 different monosaccharides: xylose (Xyl), glucose (Glc), galactose (Gal), N-acetylglucosamine and -galactosamine (GlcNAc/GalNAc), mannose (Man), fucose (Fuc), glucuronic acid (GlcA), enzymatically transformed to iduronic acid (IdoA), and sialic acid (Neu5Ac). These monosaccharides are linked via O-glycosidic linkages in $\alpha$ - or $\beta$-anomer conformation by glycosylating enzymes termed glycosyltransferases. The abundance, activity, and specificity of these enzymes and of their substrates (activated monosaccharides) determine the complexity of polysaccharides. Glycans are carbohydrate structures which contain more than one monosaccharide. They may be linear or branched. They may exist in free form but are mostly conjugated to lipids as glycosphingolipids or to proteins as GPs or proteoglycans. The glycan chains are linked to asparagine (N-glycans) or to serine or threonine (generally termed Ser/Thr-linked which comprise O-glycans and GAG conjugates, see below). The glycome is divided into GAGs and other glycan determinants. GAGs are linear glycans which consist of repetitive disaccharide units. They can occur in free form as nonsulfated hyaluronan (HA) or linked to proteins as sulfated proteoglycans. The most abundant proteoglycan is the heparan sulfate (HS) proteoglycan (-Fig. 1). All cell surface-bound glycoconjugates constitute the glycocalyx which surrounds every cell in the organism. ${ }^{1,2,16} \mathrm{HA}$ is considered to be part of the glycocalyx by some authors. ${ }^{17}$

Glycans can bind GBPs. GBPs comprise sulfated GAG-binding proteins and lectins. Sulfated GAG-binding proteins mainly interact with negatively charged sulfate groups along GAGs via clusters of positively charged amino acids. All lectins possess a carbohydrate recognition domain (CRD) with a binding pocket exhibiting variable specificity for typically terminal glycan determinants. ${ }^{18}$ Proteins which bind to the nonsulfated GAG $\mathrm{HA}$ are classified as lectins because they share conserved binding modules similar to the lectin CRD (the role of HA and the binding protein cluster of differentiation [CD] 44 [-Fig. 1] in atherosclerosis will be discussed in the section "The Glycocalyx: GAGs and GAG-Binding Proteins").

Apart from their contribution to structural scaffolding in the extracellular matrix, only those 7,000 to 8,000 of a trillion possible combinations of glycans that interact with GBPs are thought to be physiologically relevant. Therefore, GBPs provide a link between glycan structure and function. ${ }^{19}$

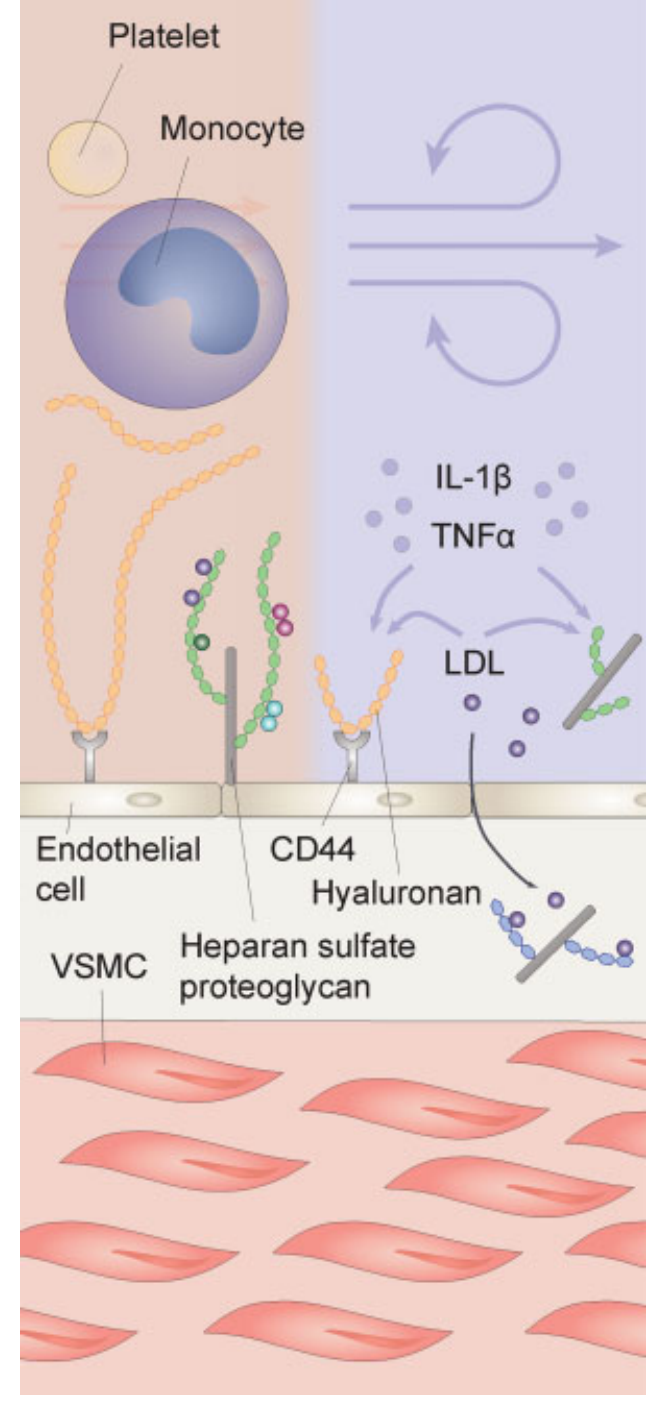

Fig. 1 The role of the endothelial glycocalyx in maintaining vascular health and its disturbance under proatherogenic conditions. The endothelial glycocalyx constitutes a sensor of blood shear stress, a barrier which prevents cells and plasma components from interacting with the endothelium and a reservoir for glycosaminoglycan (GAG)binding proteins. Its constitution is altered by disturbed blood flow, inflammatory mediators such as IL-1 $\beta$ and TNF $\alpha$, and hyperlipidemia. The depiction of pathophysiological processes is simplified. CD44, cluster of differentiation 44 ; IL-1 $\beta$, interleukin $1 \beta$; oxLDL, oxidized low-density lipoprotein; TNF $\alpha$, tumor necrosis factor $\alpha$.

\section{Challenges and Opportunities in Analyzing Glycan Structure and Function}

The complexity of glycan structures makes their identification and structural and functional analysis difficult, both in vitro and in vivo. Since glycans are not primary gene products, they cannot be genetically labeled or biochemically amplified. Redundancy in the biosynthesis of a specific glycan or embryonic lethality of genetic knockouts renders mutagenesis studies difficult. Mass spectrometry (MS)based approaches allow the identification of glycan sequences in a crude sample of glycans or glycoconjugates. However, they provide only limited information on stereoisomeric conformation and linkages. Nuclear magnetic 
resonance (NMR) spectroscopy yields a complete threedimensional structure of a determinant but requires a substantial amount of material. ${ }^{20-22}$

Techniques based on the interaction between glycans and GBPs, especially lectins, may complement MS and NMR. Provided that lectins with appropriate selectivity are available, the interaction of GBPs with low amounts of particular glycans may allow conclusions on many of their structural features. For example, microarray analyses are performed by immobilizing lectins on a surface and incubating them with labeled GPs. Variations of the technique allow comprehensive glycan profiling of glycoconjugates, live cells, or tissue extracts. ${ }^{23}$

Overall, these developments show that advanced biochemical tools are at hand to investigate the pathophysiological role of glycans which rely in part on their interaction with GBPs.

\section{Pathophysiological Relevance of Glycans in Atherosclerosis}

The vasculature senses and integrates distant and local changes in the condition of the organism and reflects these changes in part through modifications of endothelial surface glycans and free glycans shed by the endothelium into the plasma. Each of the 60 trillion endothelial cells on a surface area between 4,000 and 7,000 square meters exhibits a unique and dynamic cellular glycome. ${ }^{24-26}$ Endothelial proteoglycans protrude into the vessel lumen and cover smaller cell-bound GPs and glycolipids. Together these components form the endothelial glycocalyx. It constitutes a sensor of blood shear stress, a barrier which prevents cells and plasma components from interacting with the endothelium and a reservoir for GAG-binding proteins (- Fig. 1). ${ }^{16,17,27,28}$ Therefore, it regulates the key mechanisms of atheroprogression: the endothelial dysregulation by disturbed blood flow and pressure, platelet adhesion to the endothelium preceding leukocyte recruitment and activation, and the accumulation and phagocytosis of lipoproteins (-Fig. 2).27,29-32 Accordingly, an intact glycocalyx protects from atherosclerosis. ${ }^{16,17,24,33}$ Cardiovascular risk factors such as inflammatory cytokines, hyperlipidemia, and hyperglycemia particularly at sites of disturbed blood flow perturb its composition (-Fig. 1). ${ }^{34-37}$ However, specific components of the glycocalyx may also promote atheroprogression.

\section{The Glycocalyx: GAGs and GAG-Binding Proteins}

HS and the structurally related heparin alone bind to around 450 proteins which are implicated in hemostasis (e.g., antithrombin and VWF), inflammation (chemokines and $\mathrm{P} / \mathrm{L}-$ selectin), and lipid metabolism (apolipoproteins, LDLreceptor [LDLR], and lipoprotein lipase).$^{38}$ The specificity of their interactions with heparin and HS ranges from nonspecific mostly charge-based to very specific and may vary with the pattern of sulfation. ${ }^{39,40}$ Sulfation of endothelial HS may regulate rolling and arrest of leukocytes on the

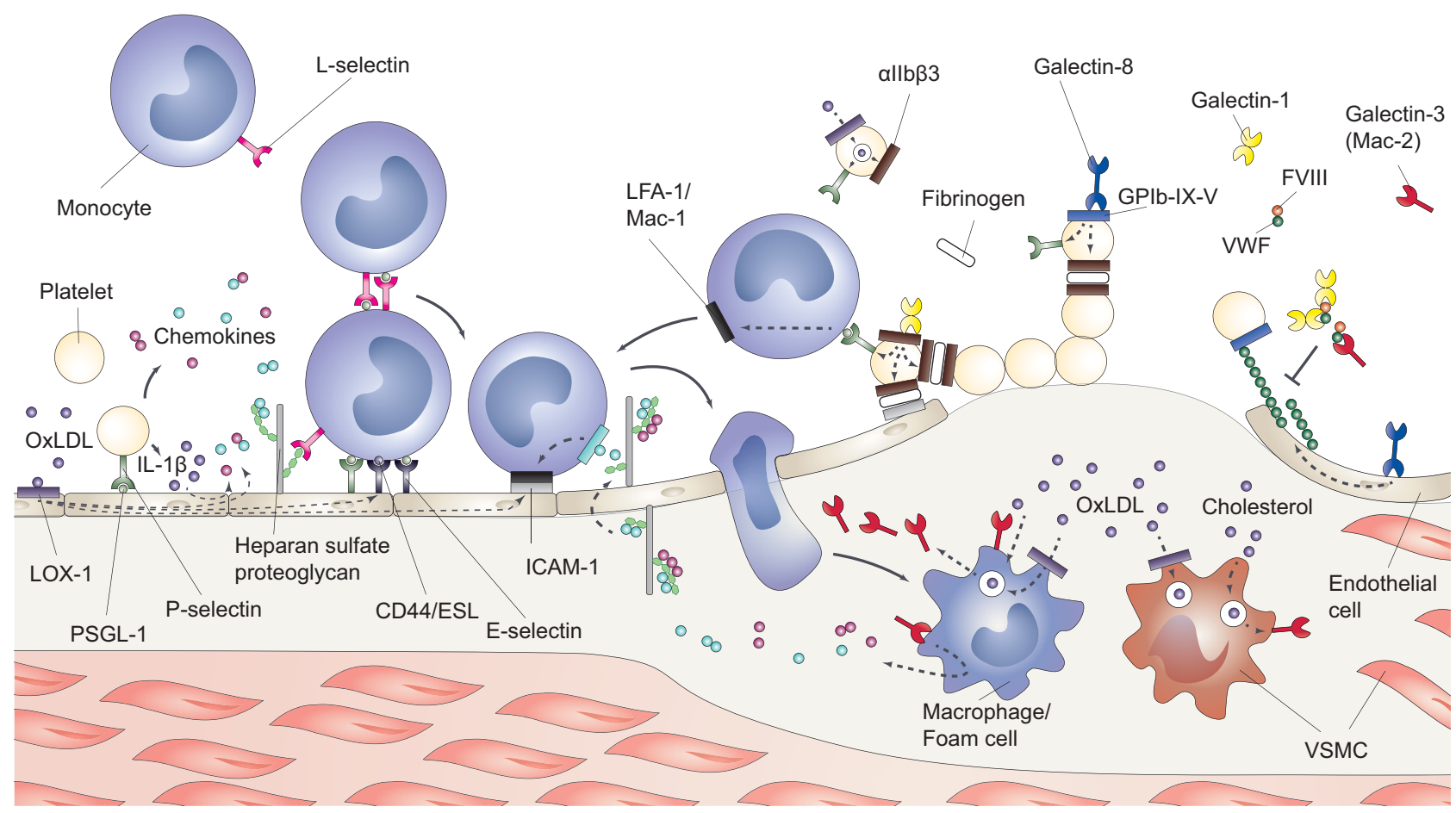

Fig. 2 Glycans and glycan-binding proteins (GBPs) in atheroprogression. The pathogenesis of atherosclerosis is characterized by endothelial dysregulation, platelet and leukocyte recruitment, the accumulation and phagocytosis of lipoproteins by macrophages and vascular smooth muscle cells (VSMCs), and thrombosis after plaque rupture. The depiction of pathophysiological processes is simplified. CD44/ESL-1, cluster of differentiation 44 and E-selectin ligand 1; FVIII, factor VIII; ICAM-1, intercellular adhesion molecule 1; IL-1 $\beta$, interleukin $1 \beta$; LFA-1/Mac-1, lymphocyte function-associated antigen 1 and macrophage-1 antigen; LOX-1, lectin-like oxidized low-density lipoprotein receptor-1; Mac-2, macrophage-2 antigen; oxLDL, oxidized low-density lipoprotein; PSGL-1, P-selectin glycoprotein ligand 1; VWF, von Willebrand factor. 
endothelium at sites of inflammation by modulating Lselectin binding, and transcytosis and presentation of chemokines to their receptors on leukocytes ( $\mathbf{- F i g . ~ 2 , ~ f o r ~ a ~ m o r e ~}$ detailed discussion on the role of selectins see the "C-type lectins" section). ${ }^{41-46}$ Heparin and its derivatives may exert an anti-inflammatory effect by blocking P- and L-selectin without affecting hemostasis. ${ }^{47}$ The expression, sulfation, and degradation of HS is regulated. For example, inflammatory cytokines such as interleukin $1 \beta$ (IL-1 $\beta$ ) differentially regulate expression and sulfation of HS in human endothelial cells in vitro and increase shedding in vivo (- Fig. 1). ${ }^{34,35}$ Interindividual differences in glycocalyx thickness, basal turnover, speed and severity of deterioration after insult, and renal excretion of HS have been suggested. ${ }^{48}$ These regulations may affect the capacity of HS to interact with selectins and chemokines (-Figs. 1 and $\mathbf{2}$ ).

HA expressed by endothelial cells in response to proinflammatory IL- $1 \beta$ and tumor necrosis factor $\alpha$ (TNF $\alpha$ ) has been shown to mediate the adhesion of monocytes to the endothelium via simultaneous interaction with leukocytic and endothelial CD $44 .{ }^{49}$ However, it is unclear whether intraluminal leukocyte-HA interactions are involved in atheroprogression.

In fact, complete inhibition of HA synthesis increased atherosclerosis in apolipoprotein $\mathrm{E}(\mathrm{ApoE})^{-1-}$ mice on a Western diet and thrombosis likely by increased interaction of monocytes and platelets with the vascular wall due to reduced steric hindrance by the glycocalyx. ${ }^{33}$ HA shedding possibly induced by hyperglycemia or TNF $\alpha$ was observed in 100 patients with type I diabetes compared with healthy controls. ${ }^{36}$

By contrast, partial inhibition of HA synthesis in vascular smooth muscle cells (VSMCs) induced by IL-1 $\beta$ after monocyte migration into atherosclerotic plaque decreased atherosclerosis. ${ }^{50}$ Interstitial HA expressed by VSMCs fosters
VSMCs migration and VSMCs switching from a contractile to a synthetic and proliferative phenotype and increases retention and activation of macrophages in the plaque. ${ }^{51}$

Furthermore, GAGs may control lipid metabolism. A reduction of $\mathrm{HS}$ and $\mathrm{HA}$ surface expression located at lesion-prone sites in the vasculature and induced by hyperlipidemia was associated with increased LDL leakage into the subendothelium (-Fig. 1). ${ }^{37}$ By contrast, subendothelial retention of LDL by direct proteoglycan-binding was critical for the progression of atherosclerosis (- Fig. 1). ${ }^{52}$ HS may also be required for the binding of proprotein convertase subtilisin/kexin type 9 (PCSK9) to hepatic LDLR which induces LDLR internalization and degradation and increases LDL plasma levels (-Fig. 3). Remarkably, it has been suggested that the liver-specific effect of PCSK9 may be based on its selective binding to hepatic HS proteoglycans (- Fig. 3). ${ }^{53}$

\section{Other Glycan Determinants and Their Lectins}

\section{C-Type Lectins}

Lectins are subdivided into evolutionary-related families based on structural similarities. The three major families of mammalian lectins in vascular biology are C-type, I-type, and galectins. The C-type constitutes the largest family of lectins. It comprises selectins, endocytic receptors which internalize and deliver their ligands to lysosomes, collectins, and several proteoglycans.

\section{Selectins}

Three types of selectins exist: E-selectin (expressed by the endothelium upon activation), P-selectin (stored in platelet $\alpha$ granules and endothelial Weibel-Palade bodies and exposed upon activation), and L-selectin (constitutively expressed on

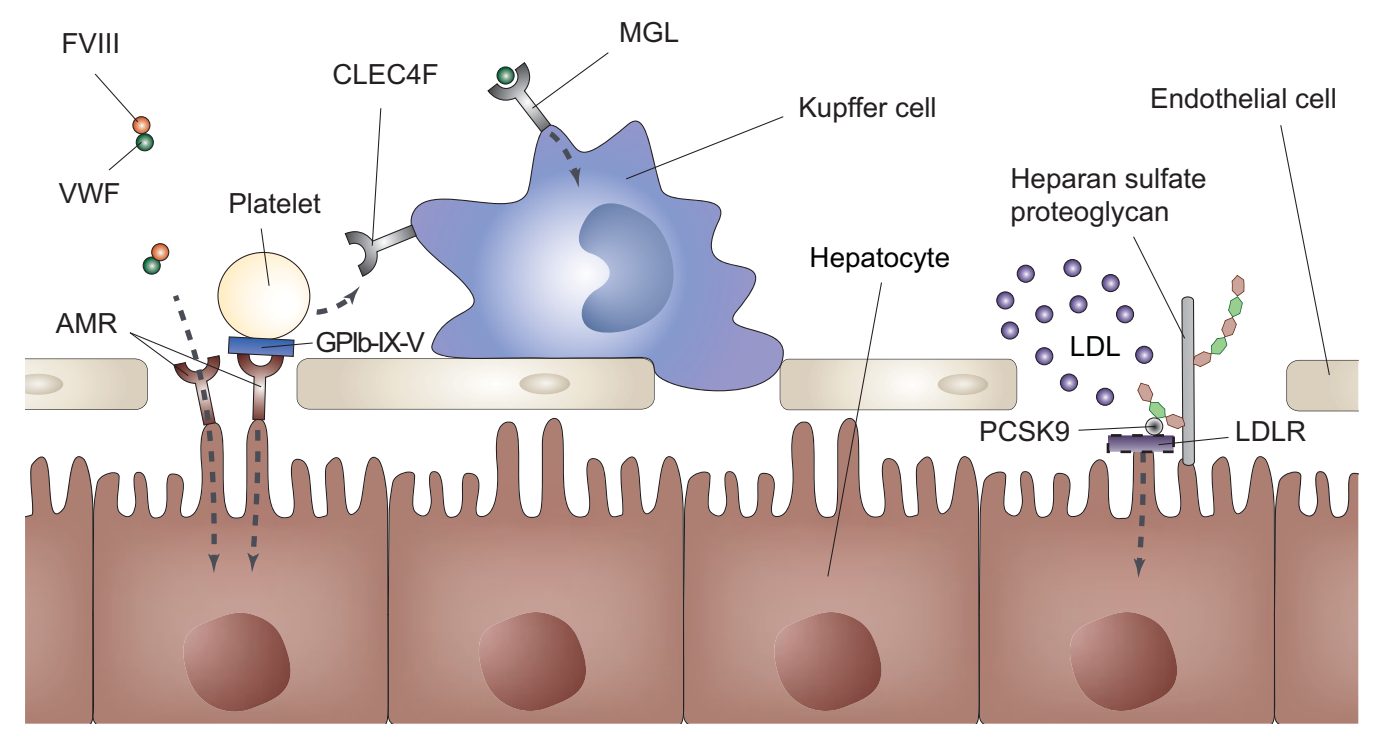

Fig. 3 Glycans and glycan-binding proteins (GBPs) in the hepatic clearance of coagulation factors and platelets and lipid metabolism. Heparan sulfate (HS) mediates the binding of PCSK9 to the hepatic LDLR which induces LDLR internalization and degradation. The AMR binds VWF, FVIII, and glycoprotein (GP) Ib-IX-V on platelets and mediates their phagocytosis. CLEC4F and MGL on Kupffer cells are involved in the hepatic clearance of platelets and VWF, respectively. The depiction of pathophysiological processes is simplified. AMR, Ashwell-Morell receptor; CLEC4F, C-type lectin domain family 4 member F; FVIII, factor VIII; LDL, low-density lipoprotein; LDLR, low-density lipoprotein receptor; MGL, macrophage galactose-type lectin; PCSK9, proprotein convertase subtilisin/kexin type 9; VWF, von Willebrand factor. 
leukocytes). Selectins promote capture, rolling, and adhesion of platelets (P-selectin) and capture and rolling of leukocytes (E-, P-, and L-selectin) on the endothelium, secondary capture between freely flowing and rolling leukocytes (L-selectin), and between leukocytes and platelets (P-selectin) in a shear stressdependent manner (-Fig. 2). ${ }^{43,54-63}$ All selectins bind the sialyl Le ${ }^{\mathrm{x}}$-tetrasaccharide, but differ in their specificity for variants of the tetrasaccharide at different sites in the vasculature as well as for the GP to which the variants are conjugated. ${ }^{60}$ While $\mathrm{P}$ - and L-selectin only bind sialyl $\mathrm{Le}^{\mathrm{x}}$ conjugated to P-selectin glycoprotein ligand 1, E-selectin also binds to CD44, E-selectin ligand 1, and, depending on cell type and pathophysiological context, CD43 and glycolipid conjugates (-Fig. 2). ${ }^{58,62}$ Because of their role in platelet rolling and adhesion and leukocyte recruitment to the vascular wall, the impact of P-, E-, and L-selectin on atheroprogression has been studied extensively. ${ }^{63,64}$

\section{The Ashwell-Morell Receptor}

Furthermore, the hepatic Ashwell-Morell receptor (AMR), an endocytic C-type lectin, is expressed on hepatocytes and specifically recognizes terminal Gal and GalNAc residues. The AMR binds VWF (defect or deficiency leads to von Willebrand disease, the most common inherited bleeding disorder), factor VIII (FVIII, defect or deficiency leads to hemophilia A), and the GPIb-IX-V on platelets via N-glycans which expose Gal residues due to deficiency in terminal Neu5Ac and mediates their phagocytosis (- Fig. 3) ${ }^{65-68}$ In line with these findings, platelets from mice deficient in the Neu5Ac-adding sialyltransferase ST3Gal-IV are removed from the circulation. ${ }^{66-68}$ A role for two other endocytic Ctype lectins, the C-type lectin domain family 4 member F and macrophage galactose-type lectin, expressed on Kupffer cells, liver-resident macrophages, in the hepatic clearance of platelets, and VWF expressing desialylated O-glycans, respectively, has recently been suggested (-Fig. 3). ${ }^{69,70}$

Interestingly, a loss of function mutation in the main component of the AMR was associated with lowering of LDL plasma levels and a reduced risk for coronary artery disease in an Icelandic case-control study with 269,344 participants. The authors suggest that the AMR may interact with a desialylated form of the LDLR and mediate its LDLindependent internalization producing an increase in LDL plasma levels. ${ }^{71}$ Moreover, it has been shown that hypersialylated LDLRs internalize LDL more effectively and mice with a deficiency in Neu5Ac-removing sialidase exhibit lower LDL plasma levels. ${ }^{72}$ Sialylation of LDL affected its uptake by macrophages. ${ }^{73}$ Notably, a SNP in the ST3Gal-IV gene was associated with increased LDL plasma levels in 95,454 patients. ${ }^{7}$ Recently, small interfering ribonucleic acid which downregulates PCSK9 in patients with elevated LDL cholesterol, was conjugated to GalNAc to specifically bind the hepatic AMR to reduce doses and side effects. ${ }^{74,75}$

Lectin-Like Oxidized Low-Density Lipoprotein Receptor-1 and Mannose-Binding Lectin

Several other endocytic C-type lectins are implicated in atherosclerosis. Although the role of glycans in their actions has not been investigated or they exert their function in a glycanindependent manner, lectin-like oxidized low-density lipoprotein receptor-1 (LOX-1) and mannose-binding lectin (MBL) will be briefly discussed. LOX-1 serves as a scavenger receptor for oxidized LDL (oxLDL) on endothelial cells (-Fig. 2). The uptake of oxLDL is atherogenic as it leads to upregulation of adhesion receptors and chemokines (-Fig. 2). LOX-1 also mediates the uptake of oxLDL by platelets, macrophages, and VSMCs (-Fig. 2). ${ }^{76,77}$ The uptake of oxLDL by platelets has recently been shown to induce the expression of P-selectin and the activation of $\alpha$ IIb $\beta 3$ integrin on platelets (-Fig. 2) and chemokine release. ${ }^{78}$ Plasma levels of shedded LOX-1 had a higher sensitivity in the diagnosis of an acute coronary syndrome than troponin $\mathrm{T}$ or high-sensitivity C-reactive protein and may potentially even predict it. ${ }^{79}$

MBL, a member of the collectin subfamily of C-type lectins, is expressed in human atherosclerotic plaque but not in healthy vascular tissue and may exert an atheroprotective effect, potentially by supporting the clearance of apoptotic cells by macrophages. ${ }^{80}$ In a case-control study with 1,309 participants, MBL plasma levels were found to correlate with the risk of myocardial infarction in patients with diabetes or hypercholesterolemia. The authors discovered that MBL binds oxLDL and suggested that it may mediate its noninflammatory clearance. ${ }^{81}$

\section{I-Type Lectins}

I-type lectins belong to the immunoglobulin superfamily. Among I-type lectins, siglecs which bind sialic acid are the best characterized subgroup. Other I-type lectins, such as the intercellular adhesion molecule 1 (ICAM-1), exhibit varying sugar-binding specificities and are less well characterized ${ }^{82}$ The glycan-dependency of the function of I-type lectins is unclear.

ICAM-1 mediates the adhesion of platelets and the arrest of leukocytes on the endothelium by interacting with platelet $\alpha$ IIb $\beta 3$ via fibrinogen as bridging molecule or lymphocyte function associated antigen 1 (LFA-1) and macrophage-1 antigen (Mac-1) integrins (-Fig. 2) ${ }^{25,41,55,83}$

Siglec-1 is expressed in atherosclerotic plaques from $\mathrm{ApoE}^{-1-}$ mice on a Western diet. ${ }^{84}$ Siglec-1 knockdown reduced atherosclerotic plaque formation, macrophage accumulation in plaque, and cytokine expression by atherosclerotic plaque, and by endothelial cells. Furthermore, oxLDL uptake and subsequent cytokine secretion by macrophages in vitro was mediated by Siglec- $1 .^{84,85}$ Siglec- 1 expression in blood monocytes was significantly higher in patients with coronary artery disease compared with healthy controls. ${ }^{86} \mathrm{~A}$ higher expression of Siglec-3 in classical monocytes correlated with a higher uptake of acetylated LDL particles. ${ }^{87}$

\section{Galectins}

Galectins share sequence homology in their CRDs and binding affinity for $\beta$-galactose-containing glycoconjugates. Three different types exist in humans: the prototype which consists of a single CRD, the chimera-type galectin-3 (Gal-3) that contains a CRD and an N-terminal tail, and the tandemrepeat type which comprises two CRDs connected by a linker. 
Galectins may form noncovalently bound homo- or heterooligomers. ${ }^{88,89}$ Galectins play a prominent role in atherosclerosis by regulating coagulation factors, activating platelets, affecting leukocyte adhesion and migration, and the phagocytosis of LDL. They differ in their affinity for specific glycans. ${ }^{90}$

On the one hand, galectin-1 (Gal-1) and Gal-3 exhibit anticoagulant effects by interacting with $\mathrm{N}$-glycans on VWF and preventing the formation of VWF bundles on the endothelium which interact with platelets via GPIb-IX-V to promote thrombosis (-Fig. 2). ${ }^{55,91}$ As a result, Gal-1 ${ }^{-1-} / \mathrm{Gal}-$ $3^{-1-}$ mice show more arterial thrombi. ${ }^{91} \mathrm{Gal}-1$ binds to Nglycans on FVIII associated with VWF and reduces its activity (-Fig. 2). The authors speculate that Gal-1 may modulate FVIII plasma levels by mediating its endocytosis in the liver. ${ }^{92}$ On the other hand, Gal-1 induces P-selectin expression and aggregation of platelets by binding to the integrin $\alpha \operatorname{IIb} \beta 3$ in a glycan-dependent manner (-Fig. 2). ${ }^{93,94}$ The aggregation of platelets and interaction of platelets with the endothelium is induced by the upregulation of $\alpha \operatorname{IIb} \beta 3$. Integrin $\alpha \operatorname{IIb} \beta 3$ interacts with other platelet $\alpha$ IIb $\beta 3$ and endothelial ICAM1 via fibrinogen (-Fig. 2). Fibrinogen also mediates the interaction of platelet $\alpha$ IIb $\beta 3$ with the endothelial integrin $\alpha \mathrm{V} \beta 3$ (not shown). ${ }^{55,95}$ Furthermore, it has been demonstrated that platelet $\alpha$ IIb $\beta 3$ interacts with endothelial GPIbIX-V and $\alpha V \beta 3$ via VWF and with endothelial $\alpha \mathrm{V} \beta 3$ via fibronectin (not shown). Fibrinogen, VWF, and fibronectin are expressed by platelets and released upon activation. ${ }^{55,95}$ Platelet adhesion to the endothelium and platelet aggregation induce platelet activation and endothelial activation by platelet IL-1 $\beta$ and upregulation of adhesion receptors and release of chemokines in both cell types (- Fig. 2)..$^{32,54}$

The effect of Gal-8 is more consistent. It induces the endothelial expression of VWF and promotes platelet adhesion to the endothelium (-Fig. 2). ${ }^{96}$ It also fosters P-selectin expression and platelet aggregation by binding platelet GPIbIX-V in a glycan-dependent manner (- Fig. 2). ${ }^{97}$

The best characterized galectin in atherosclerosis is Gal-3 (Mac-2). Monocytes strongly upregulate Gal-3 when they differentiate into macrophages which accumulate in mouse and human atherosclerotic plaques. ${ }^{98-100} \mathrm{Gal}-3$ mediates the uptake of oxLDL, and oxLDL increases Gal-3 expression (-Fig. 2). ${ }^{101,102}$ It has also been shown that VSMCs upregulate Gal-3 after cholesterol uptake and transdifferentiation into a macrophage-like phenotype (-Fig. 2). ${ }^{103}$ Moreover, Gal-3 may attract monocytes either directly or by inducing the expression of chemokines in a glycan-dependent manner (-Fig. 2). ${ }^{98,99} \mathrm{Gal}_{-3} 3^{-1-} / \mathrm{ApoE}^{-1-}$ mice and $\mathrm{ApoE}^{-1-}$ mice treated with a glycan to block the Gal-3 CRD exhibit less atherosclerotic lesions and inflammatory plaque infiltrates. ${ }^{98,104}$

\section{Therapeutic Potential of Glycans and GBPs in Atherosclerosis}

The implication of glycans and GBPs in the pathophysiology of atherosclerosis raises interesting therapeutic and diagnostic opportunities. For example, synthetic heparins and HS with specific anti-inflammatory, anticoagulant, or lipid-low- ering capacities may be customized for the individual patient and the disease state. This approach may limit unwanted side effects or conversely exploit the manifold potential of heparins. Detection of specific variants of endogenous HS in plasma may prove useful for the assessment of the condition of the vascular system. ${ }^{48}$

Furthermore, biological or synthetic lectins may specifically bind a particular glycan and prevent it from interacting with its receptor. Moreover, the possibility to specifically target the liver with a compound conjugated to a simple monosaccharide is intriguing. ${ }^{74,75}$ The approach may be applied to reach other organs. The analysis of the glycosylation profile of GPs, platelets, or LDL particles for diagnostic purposes seems promising.

Biological and synthetic lectins may lend themselves as therapeutics. Galectins for example may be used to specifically target thrombosis or serve as an intermediary between a pharmaceutical and its target. One may also block the CRD of galectins and other lectins with metabolically inert glycans to interfere with their function. Lectins may also serve as biomarkers. ${ }^{79}$

Exploiting these targets may address so far underappreciated pathways and limit side effects of pharmaceuticals which result from their insufficient specificity to diseased tissue.

\section{Conclusion}

Glycans and GBPs constitute a complex and often highly specific system. This system is accessible to analytical techniques which rely in part on their interaction. Both glycans and their binding partners are heavily involved in key mechanisms of the pathogenesis of atherosclerosis, thrombosis, leukocyte adhesion and migration, and lipid metabolism. Activated monosaccharides or more complex glycan determinants, therapeutics conjugated to monosaccharides, or lectins may be used to specifically prevent or inhibit the development of the disease. The analysis of altered glycan structures on GPs, platelets, LDL particles, or differently expressed lectins may serve diagnostic purposes. With the exception of heparin and its derivatives, very few glycan-based compounds have reached the market. The glycome therefore represents a promising and underappreciated tool and target for future pharmaceutical developments in atherosclerosis.

\section{Funding}

This work was supported by Deutsche Forschungsgemeinschaft (SFB914 B08 [to C.W.], SFB1123 A1 [to C. W.], A2 [to P.v.H], INST 409/150-1 FUGG [to C.W.]).

\section{Conflict of Interest}

None declared.

\section{References}

1 Rakus JF, Mahal LK. New technologies for glycomic analysis: toward a systematic understanding of the glycome. Annu Rev Anal Chem (Palo Alto, Calif) 2011;4:367-392

2 Ohtsubo K, Marth JD. Glycosylation in cellular mechanisms of health and disease. Cell 2006;126(05):855-867 
3 Landsteiner K. Ueber Agglutinationserscheinungen normalen menschlichen Blutes. Wien Klin Wochenschr 1901;46:1132-1134

4 Watkins WM, Morgan WTJ. Neutralization of the anti-H agglutinin in eel serum by simple sugars. Nature 1952;169 (4307):825-826

5 Watkins WM, Morgan WTJ. Inhibition by simple sugars of enzymes which decompose the blood-group substances. Nature 1955;175(4459):676-677

6 Schunkert H, König IR, Kathiresan S, et al; Cardiogenics; CARDIoGRAM Consortium. Large-scale association analysis identifies 13 new susceptibility loci for coronary artery disease. Nat Genet 2011;43(04):333-338

7 Teslovich TM, Musunuru K, Smith AV, et al. Biological, clinical and population relevance of 95 loci for blood lipids. Nature 2010; 466(7307):707-713

8 Reilly MP, Li M, He J, et al; Myocardial Infarction Genetics Consortium; Wellcome Trust Case Control Consortium. Identification of ADAMTS7 as a novel locus for coronary atherosclerosis and association of $\mathrm{ABO}$ with myocardial infarction in the presence of coronary atherosclerosis: two genome-wide association studies. Lancet 2011;377(9763):383-392

9 Zhong M, Zhang H, Reilly JP, et al. ABO blood group as a model for platelet glycan modification in arterial thrombosis. Arterioscler Thromb Vasc Biol 2015;35(07):1570-1578

10 Stillmark H. Ueber Ricin, ein giftiges Ferment aus den Samen von Ricinus comm. L. und einigen anderen Euphorbiaceen [M. D. dissertation]. Dorpat: Kaiserliche Universität zu Dorpat; 1888

11 Gabius H-J, Siebert H-C, André S, Jiménez-Barbero J, Rüdiger H. Chemical biology of the sugar code. ChemBioChem 2004;5(06): 740-764

12 Sharon N, Lis H. History of lectins: from hemagglutinins to biological recognition molecules. Glycobiology 2004;14(11): 53R-62R

13 Lindahl U. Heparan sulfate-protein interactions-a concept for drug design? Thromb Haemost 2007;98(01):109-115

14 Petitou M, van Boeckel CAA. A synthetic antithrombin III binding pentasaccharide is now a drug! What comes next? Angew Chem Int Ed Engl 2004;43(24):3118-3133

15 Mueller RL, Scheidt S. History of drugs for thrombotic disease. Discovery, development, and directions for the future. Circulation 1994;89(01):432-449

16 Marki A, Esko JD, Pries AR, Ley K. Role of the endothelial surface layer in neutrophil recruitment. J Leukoc Biol 2015;98(04): 503-515

17 Tarbell JM, Cancel LM. The glycocalyx and its significance in human medicine. J Intern Med 2016;280(01):97-113

18 Taylor ME, Drickamer K, Schnaar RL, Etzler ME, Varki A. Discovery and classification of glycan-binding proteins. In: Varki A, Cummings RD, Esko JD, et al, eds. Essentials of Glycobiology. Cold Spring Harbor: Cold Spring Harbor Laboratory Press; 2015: 361-372

19 Cummings RD. The repertoire of glycan determinants in the human glycome. Mol Biosyst 2009;5(10):1087-1104

20 Yang Y, Franc V, Heck AJR. Glycoproteomics: a balance between high-throughput and in-depth analysis. Trends Biotechnol 2017; 35(07):598-609

21 Palaniappan KK, Bertozzi CR. Chemical glycoproteomics. Chem Rev 2016;116(23):14277-14306

22 Smith DF, Cummings RD. Application of microarrays for deciphering the structure and function of the human glycome. Mol Cell Proteomics 2013;12(04):902-912

23 Hirabayashi J, Yamada M, Kuno A, Tateno H. Lectin microarrays: concept, principle and applications. Chem Soc Rev 2013;42(10): $4443-4458$

24 Sieve I, Münster-Kühnel AK, Hilfiker-Kleiner D. Regulation and function of endothelial glycocalyx layer in vascular diseases. Vascul Pharmacol 2018;100:26-33
25 Scott DW, Patel RP. Endothelial heterogeneity and adhesion molecules N-glycosylation: implications in leukocyte trafficking in inflammation. Glycobiology 2013;23(06):622-633

26 Aird WC. Spatial and temporal dynamics of the endothelium. J Thromb Haemost 2005;3(07):1392-1406

27 Hahn C, Schwartz MA. Mechanotransduction in vascular physiology and atherogenesis. Nat Rev Mol Cell Biol 2009;10(01): 53-62

28 Handel TM, Johnson Z, Crown SE, Lau EK, Proudfoot AE. Regulation of protein function by glycosaminoglycans-as exemplified by chemokines. Annu Rev Biochem 2005;74:385-410

29 Weber C, Badimon L, Mach F, van der Vorst EPC. Therapeutic strategies for atherosclerosis and atherothrombosis: past, present and future. Thromb Haemost 2017;117(07):1258-1264

30 Gisterå $\mathrm{A}$, Hansson GK. The immunology of atherosclerosis. Nat Rev Nephrol 2017;13(06):368-380

31 Reitsma S, Oude Egbrink MGA, Heijnen VVT, et al. Endothelial glycocalyx thickness and platelet-vessel wall interactions during atherogenesis. Thromb Haemost 2011;106(05):939-946

32 Massberg S, Brand K, Grüner S, et al. A critical role of platelet adhesion in the initiation of atherosclerotic lesion formation. J Exp Med 2002;196(07):887-896

33 Nagy N, Freudenberger T, Melchior-Becker A, et al. Inhibition of hyaluronan synthesis accelerates murine atherosclerosis: novel insights into the role of hyaluronan synthesis. Circulation 2010; 122(22):2313-2322

34 Reine TM, Kusche-Gullberg M, Feta A, Jenssen T, Kolset SO. Heparan sulfate expression is affected by inflammatory stimuli in primary human endothelial cells. Glycoconj J 2012;29(01): 67-76

35 Nieuwdorp M, Meuwese MC, Mooij HL, et al. Tumor necrosis factor- $\alpha$ inhibition protects against endotoxin-induced endothelial glycocalyx perturbation. Atherosclerosis 2009;202(01): 296-303

36 Nieuwdorp M, Holleman F, de Groot E, et al. Perturbation of hyaluronan metabolism predisposes patients with type 1 diabetes mellitus to atherosclerosis. Diabetologia 2007;50(06): 1288-1293

37 van den Berg BM, Spaan JAE, Vink H. Impaired glycocalyx barrier properties contribute to enhanced intimal low-density lipoprotein accumulation at the carotid artery bifurcation in mice. Pflugers Arch 2009;457(06):1199-1206

38 Ori A, Wilkinson MC, Fernig DG. A systems biology approach for the investigation of the heparin/heparan sulfate interactome. J Biol Chem 2011;286(22):19892-19904

39 Ricard-Blum S, Lisacek F. Glycosaminoglycanomics: where we are. Glycoconj J 2017;34(03):339-349

$40 \mathrm{Xu} \mathrm{D}$, Esko JD. Demystifying heparan sulfate-protein interactions. Annu Rev Biochem 2014;83:129-157

41 Gerhardt T, Ley K. Monocyte trafficking across the vessel wall. Cardiovasc Res 2015;107(03):321-330

42 Axelsson J, Xu D, Kang BN, et al. Inactivation of heparan sulfate 2O-sulfotransferase accentuates neutrophil infiltration during acute inflammation in mice. Blood 2012;120(08):1742-1751

43 Wang L, Fuster M, Sriramarao P, Esko JD. Endothelial heparan sulfate deficiency impairs L-selectin- and chemokine-mediated neutrophil trafficking during inflammatory responses. Nat Immunol 2005;6(09):902-910

44 Koenen RR, von Hundelshausen P, Nesmelova IV, et al. Disrupting functional interactions between platelet chemokines inhibits atherosclerosis in hyperlipidemic mice. Nat Med 2009;15(01): 97-103

45 von Hundelshausen P, Koenen RR, Sack M, et al. Heterophilic interactions of platelet factor 4 and RANTES promote monocyte arrest on endothelium. Blood 2005;105(03):924-930

46 von Hundelshausen P, Agten SM, Eckardt V, et al. Chemokine interactome mapping enables tailored intervention in acute and chronic inflammation. Sci Transl Med 2017;9(384):eaah6650 
47 Wang L, Brown JR, Varki A, Esko JD. Heparin's anti-inflammatory effects require glucosamine 6-O-sulfation and are mediated by blockade of L- and P-selectins. J Clin Invest 2002;110(01): 127-136

48 Rehm M, Bruegger D, Christ F, et al. Shedding of the endothelial glycocalyx in patients undergoing major vascular surgery with global and regional ischemia. Circulation 2007;116(17): 1896-1906

49 Vigetti D, Genasetti A, Karousou E, et al. Proinflammatory cytokines induce hyaluronan synthesis and monocyte adhesion in human endothelial cells through hyaluronan synthase 2 (HAS2) and the nuclear factor-kappaB (NF-kappaB) pathway. J Biol Chem 2010;285(32):24639-24645

50 Homann S, Grandoch M, Kiene LS, et al. Hyaluronan synthase 3 promotes plaque inflammation and atheroprogression. Matrix Biol 2018;66:67-80

51 Grandoch M, Bollyky PL, Fischer JW. Hyaluronan: a master switch between vascular homeostasis and inflammation. Circ Res 2018;122(10):1341-1343

52 Skålén K, Gustafsson M, Rydberg EK, et al. Subendothelial retention of atherogenic lipoproteins in early atherosclerosis. Nature 2002;417(6890):750-754

53 Gustafsen C, Olsen D, Vilstrup J, et al. Heparan sulfate proteoglycans present PCSK9 to the LDL receptor. Nat Commun 2017; 8(01):503

54 Weber $C$. Platelets and chemokines in atherosclerosis: partners in crime. Circ Res 2005;96(06):612-616

55 Coenen DM, Mastenbroek TG, Cosemans JMEM. Platelet interaction with activated endothelium: mechanistic insights from microfluidics. Blood 2017;130(26):2819-2828

56 McEver RP. Selectins: initiators of leucocyte adhesion and signalling at the vascular wall. Cardiovasc Res 2015;107(03): 331-339

57 Wagner DD, Frenette PS. The vessel wall and its interactions. Blood 2008;111(11):5271-5281

58 Sperandio M, Gleissner CA, Ley K. Glycosylation in immune cell trafficking. Immunol Rev 2009;230(01):97-113

59 Eriksson EE, Xie X, Werr J, Thoren P, Lindbom L. Importance of primary capture and L-selectin-dependent secondary capture in leukocyte accumulation in inflammation and atherosclerosis in vivo. J Exp Med 2001;194(02):205-218

60 Cambi A, Figdor CG. Dual function of C-type lectin-like receptors in the immune system. Curr Opin Cell Biol 2003;15(05):539-546

61 Sperandio M, Smith ML, Forlow SB, et al. P-selectin glycoprotein ligand-1 mediates L-selectin-dependent leukocyte rolling in venules. J Exp Med 2003;197(10):1355-1363

62 Zarbock A, Ley K, McEver RP, Hidalgo A. Leukocyte ligands for endothelial selectins: specialized glycoconjugates that mediate rolling and signaling under flow. Blood 2011;118(26): 6743-6751

63 An G, Wang H, Tang R, et al. P-selectin glycoprotein ligand-1 is highly expressed on Ly-6Chi monocytes and a major determinant for Ly-6Chi monocyte recruitment to sites of atherosclerosis in mice. Circulation 2008;117(25):3227-3237

64 Dong ZM, Chapman SM, Brown AA, Frenette PS, Hynes RO, Wagner DD. The combined role of P- and E-selectins in atherosclerosis. J Clin Invest 1998;102(01):145-152

65 Quach ME, Chen W, Li R. Mechanisms of platelet clearance and translation to improve platelet storage. Blood 2018;131(14): 1512-1521

66 Wandall HH, Rumjantseva V, Sørensen AL, et al. The origin and function of platelet glycosyltransferases. Blood 2012;120(03): 626-635

67 Sørensen AL, Rumjantseva V, Nayeb-Hashemi S, et al. Role of sialic acid for platelet life span: exposure of $\beta$-galactose results in the rapid clearance of platelets from the circulation by asialoglycoprotein receptor-expressing liver macrophages and hepatocytes. Blood 2009;114(08):1645-1654
68 Grewal PK, Uchiyama S, Ditto D, et al. The Ashwell receptor mitigates the lethal coagulopathy of sepsis. Nat Med 2008;14 (06):648-655

69 Ward SE, O'Sullivan JM, Drakeford C, et al. A novel role for the macrophage galactose-type lectin receptor in mediating von Willebrand factor clearance. Blood 2018;131(08):911-916

70 Li Y, Fu J, Ling Y, et al. Sialylation on O-glycans protects platelets from clearance by liver Kupffer cells. Proc Natl Acad Sci U S A 2017;114(31):8360-8365

71 Nioi P, Sigurdsson A, Thorleifsson G, et al. Variant ASGR1 associated with a reduced risk of coronary artery disease. N Engl J Med 2016;374(22):2131-2141

72 Yang A, Gyulay G, Mitchell M, White E, Trigatti BL, Igdoura SA. Hypomorphic sialidase expression decreases serum cholesterol by downregulation of VLDL production in mice. J Lipid Res 2012; 53(12):2573-2585

73 Bartlett AL, Grewal T, De Angelis E, Myers S, Stanley KK. Role of the macrophage galactose lectin in the uptake of desialylated LDL. Atherosclerosis 2000;153(01):219-230

74 Ray KK, Landmesser U, Leiter LA, et al. Inclisiran in patients at high cardiovascular risk with elevated LDL cholesterol. N Engl J Med 2017;376(15):1430-1440

75 Nair JK, Willoughby JLS, Chan A, et al. Multivalent N-acetylgalactosamine-conjugated siRNA localizes in hepatocytes and elicits robust RNAi-mediated gene silencing. J Am Chem Soc 2014;136(49):16958-16961

76 Pothineni NVK, Karathanasis SK, Ding Z, Arulandu A, Varughese $\mathrm{KI}$, Mehta JL. LOX-1 in atherosclerosis and myocardial ischemia: biology, genetics, and modulation. J Am Coll Cardiol 2017;69 (22):2759-2768

77 Chen M, Kakutani M, Naruko T, et al. Activation-dependent surface expression of LOX-1 in human platelets. Biochem Biophys Res Commun 2001;282(01):153-158

78 Chatterjee M, Rath D, Schlotterbeck J, et al. Regulation of oxidized platelet lipidome: implications for coronary artery disease. Eur Heart J 2017;38(25):1993-2005

79 Hayashida K, Kume N, Murase T, et al. Serum soluble lectin-like oxidized low-density lipoprotein receptor-1 levels are elevated in acute coronary syndrome: a novel marker for early diagnosis. Circulation 2005;112(06):812-818

80 Matthijsen RA, de Winther MPJ, Kuipers D, et al. Macrophagespecific expression of mannose-binding lectin controls atherosclerosis in low-density lipoprotein receptor-deficient mice. Circulation 2009;119(16):2188-2195

81 Saevarsdottir S, Oskarsson OO, Aspelund T, et al. Mannan binding lectin as an adjunct to risk assessment for myocardial infarction in individuals with enhanced risk. J Exp Med 2005;201(01): 117-125

82 Varki A, Schnaar RL, Crocker PR. I-type lectins. In: Varki A, Cummings RD, Esko JD, et al, eds. Essentials of Glycobiology. Cold Spring Harbor: Cold Spring Harbor Laboratory Press; 2015: 453-467

83 Ley K, Laudanna C, Cybulsky MI, Nourshargh S. Getting to the site of inflammation: the leukocyte adhesion cascade updated. Nat Rev Immunol 2007;7(09):678-689

84 Xiong Y-S, Wu A-L, Lin Q-S, et al. Contribution of monocytes Siglec-1 in stimulating $\mathrm{T}$ cells proliferation and activation in atherosclerosis. Atherosclerosis 2012;224(01):58-65

85 Xiong Y-S, Wu A-L, Mu D, et al. Inhibition of siglec- 1 by lentivirus mediated small interfering RNA attenuates atherogenesis in apoE-deficient mice. Clin Immunol 2017;174:32-40

86 Xiong Y-S, Zhou Y-H, Rong G-H, et al. Siglec-1 on monocytes is a potential risk marker for monitoring disease severity in coronary artery disease. Clin Biochem 2009;42(10-11):1057-1063

87 Draude G, von Hundelshausen P, Frankenberger M, ZieglerHeitbrock HW, Weber C. Distinct scavenger receptor expression and function in the human CD14(+)/CD16(+) monocyte subset. Am J Physiol 1999;276(04):H1144-H1149 
88 Miller MC, Ludwig A-K, Wichapong K, et al. Adhesion/growthregulatory galectins tested in combination: evidence for formation of hybrids as heterodimers. Biochem J 2018;475(05):1003-1018

89 Gabius H-J, Manning JC, Kopitz J, André S, Kaltner H. Sweet complementarity: the functional pairing of glycans with lectins. Cell Mol Life Sci 2016;73(10):1989-2016

90 Stowell SR, Arthur CM, Mehta P, et al. Galectin-1, -2, and -3 exhibit differential recognition of sialylated glycans and blood group antigens. J Biol Chem 2008;283(15):10109-10123

91 Saint-Lu N, Oortwijn BD, Pegon JN, et al. Identification of galectin-1 and galectin-3 as novel partners for von Willebrand factor. Arterioscler Thromb Vasc Biol 2012;32(04):894-901

92 O'Sullivan JM, Jenkins PV, Rawley O, et al. Galectin-1 and galectin-3 constitute novel-binding partners for factor VIII. Arterioscler Thromb Vasc Biol 2016;36(05):855-863

93 Romaniuk MA, Croci DO, Lapponi MJ, et al. Binding of galectin-1 to $\alpha \mathrm{IIb} \beta_{3}$ integrin triggers “outside-in" signals, stimulates platelet activation, and controls primary hemostasis. FASEB J 2012;26 (07):2788-2798

94 Pacienza N, Pozner RG, Bianco GA, et al. The immunoregulatory glycan-binding protein galectin-1 triggers human platelet activation. FASEB J 2008;22(04):1113-1123

95 Bombeli T, Schwartz BR, Harlan JM. Adhesion of activated platelets to endothelial cells: evidence for a GPIIbIIIa-dependent bridging mechanism and novel roles for endothelial intercellular adhesion molecule 1 (ICAM-1), alphavbeta3 integrin, and GPIbalpha. J Exp Med 1998;187(03):329-339

96 Cattaneo V, Tribulatti MV, Carabelli J, Carestia A, Schattner M, Campetella O. Galectin-8 elicits pro-inflammatory activities in the endothelium. Glycobiology 2014;24(10):966-973
97 Romaniuk MA, Tribulatti MV, Cattaneo V, et al. Human platelets express and are activated by galectin-8. Biochem J 2010;432(03): 535-547

98 MacKinnon AC, Liu X, Hadoke PWF, Miller MR, Newby DE, Sethi T. Inhibition of galectin-3 reduces atherosclerosis in apolipoprotein E-deficient mice. Glycobiology 2013;23(06): 654-663

99 Papaspyridonos M, McNeill E, de Bono JP, et al. Galectin-3 is an amplifier of inflammation in atherosclerotic plaque progression through macrophage activation and monocyte chemoattraction. Arterioscler Thromb Vasc Biol 2008;28(03):433-440

100 Liu F-T, Hsu DK, Zuberi RI, Kuwabara I, Chi EY, Henderson WR Jr. Expression and function of galectin-3, a $\beta$-galactoside-binding lectin, in human monocytes and macrophages. Am J Pathol 1995; 147(04):1016-1028

101 Kim K, Mayer EP, Nachtigal M. Galectin-3 expression in macrophages is signaled by Ras/MAP kinase pathway and up-regulated by modified lipoproteins. Biochim Biophys Acta 2003;1641(01): 13-23

102 Zhu W, Sano H, Nagai R, Fukuhara K, Miyazaki A, Horiuchi S. The role of galectin-3 in endocytosis of advanced glycation end products and modified low density lipoproteins. Biochem Biophys Res Commun 2001;280(04):1183-1188

103 Rong JX, Shapiro M, Trogan E, Fisher EA. Transdifferentiation of mouse aortic smooth muscle cells to a macrophage-like state after cholesterol loading. Proc Natl Acad Sci U S A 2003;100(23): 13531-13536

104 Nachtigal M, Ghaffar A, Mayer EP. Galectin-3 gene inactivation reduces atherosclerotic lesions and adventitial inflammation in ApoE-deficient mice. Am J Pathol 2008;172(01):247-255 